\title{
DIREITOS DA NATUREZA: O RIO AMAZONAS COMANDA A VIDA
}

\section{NATURE RIGHTS: THE AMAZON RIVER COMMANDS LIFE}

\section{VALMIR CÉSAR POZZETTI}

Doutor em Biodireito/Direito Ambiental pela Université de Limoges/França. Mestre em Direito do Urbanismo e do Meio Ambiente pela Université de Limoges/França. Professor Adjunto da Universidade Federal do Amazonas - UFAM e da Universidade do Estado do Estado do Amazonas - UEA. Advogado. E-mail: v_pozzetti@hotmail.com.

\section{LEONARDO LEITE NASCIMENTO}

Doutorando do Programa de Pós-graduação em Ciências Jurídicas da Universidade Federal da Paraíba - UFPB. Mestre em Direito Ambiental pela Universidade do Estado do Amazonas - UEA. Professor em cursos de pós-graduação e graduação de Direito. Oficial do Exército Brasileiro. E-mail: In0881ensino@gmail.com.

\section{RESUMO}

O rio Amazonas constitui um objeto natural, cujas águas comandam a vida dos ecossistemas e das comunidades na Pan-Amazônia. As águas amazônicas nutrem a vida de uma diversidade de ecossistemas, que apresentam vastas espécies animais e vegetais, que dependem da integridade do rio Amazonas para existirem. Não é diferente a relação dos povos tradicionais e das comunidades indígenas com as águas amazônicas compartilhadas, pois ancestralmente dependem do rio e, culturalmente, têm uma relação de existência, vivem em e de suas águas, respeitando e integrando harmonicamente a Amazônia, há muitos anos e gerações. O objetivo da pesquisa foi o de analisar o reconhecimento dos Direitos da Natureza, frente ao colapso climático global e a inefetividade das normas internacionais que tutelam o meio ambiente. Foi 
utilizado o método de pesquisa dedutivo e técnicas de pesquisa bibliográfica. Concluise que é possível a tutela jurídica do rio Amazonas, como um bem ambiental, sujeito de direitos bioculturais, em face da existência de leis, constituições e decisões de Tribunais Constitucionais globais análogas, com base na Convenção da Biodiversidade e no seu reconhecimento como patrimônio cultural imaterial. Para tanto, o Tratado de Cooperação Amazônica deve ser interpretado de acordo com os princípios jurídicos bióticos da Convenção sobre Diversidade Biológica. E o rio Amazonas, em face das tradições, das práticas sociais e rituais das comunidades que vivem em suas margens, deve ser reconhecido como patrimônio cultural imaterial, por sua grandiosidade natural e pela diversidade cultural que nele existe e dele faz parte: o rio, somos nós, nós somos o rio.

PALAVRAS-CHAVE: Rio Amazonas; Direitos da Natureza; Biodiversidade; Patrimônio cultural imaterial.

\section{ABSTRACT}

The Amazon River is a natural object whose waters command the life of ecosystems and communities in the Pan-Amazon. The Amazonian waters maintain the life of a diversity of ecosystems, which present vast animal and vegetal species, that depend on the integrity of the Amazon river to exist. It is not different the relationship of traditional peoples and indigenous communities with the shared Amazonian waters, since they ancestrally depend on the river and, culturally, have a relation of existence, live in and of their waters, respecting and harmoniously integrating the Amazon, many years ago and generations. The objective of the research was to analyze the recognition of the Rights of Nature in the face of global climate collapse and the ineffectiveness of the international norms that protect the environment. The method of deductive research and bibliographic research techniques was used. It is concluded that the legal protection of the Amazon River is possible, as an environment good, subject of biocultural rights, due to the existence of laws, constitutions and decisions of similar global Constitutional Courts, based on the Biodiversity Convention and it's 
recognition as intangible cultural heritage. To this end, the Amazon Cooperation Treaty must be interpreted in accordance with the biotic legal principles of the Convention on Biological Diversity. And the Amazon River, in view of the traditions, social practices and rituals of the communities that live along its banks, must be recognized as intangible cultural heritage, for its natural grandeur and for the cultural diversity that exists in it and it is part of it: the river, it's us, we're the river.

KEYWORDS: Amazon River; Rights of Nature; Biodiversity; Intangible cultural heritage.

\section{INTRODUÇÃO}

O rio Amazonas é o maior rio do mundo; suas águas são compartilhadas no contexto da Bacia Amazônica, e cruzam fronteiras de Estados soberanos, dos Andes até encontrar a foz no Oceano Atlântico. As águas amazônicas nutrem a vida de uma diversidade de ecossistemas, que apresentam vastas espécies animais e vegetais, que dependem da integridade do rio Amazonas para existirem.

A relação dos povos tradicionais e das comunidades indígenas com as águas amazônicas compartilhadas, precede a população atual; pois seus ancestrais já dependiam do rio e, culturalmente, têm uma relação de existência, vivem "em" e "de" suas águas, respeitando e integrando harmonicamente a Amazônia, há muitos anos e gerações.

Todavia, o interesse econômico sobre as riquezas da biodiversidade da Floresta Amazônica, ao longo dos séculos, tem provocado grande desequilíbrio na relação homem-natureza e homem-comunidades indígenas, em especial no uso do rio. As águas amazônicas eram caminhos e hoje constituem-se em um bem econômico, entre outros usos, para geração de energia elétrica e talvez, em um breve futuro, para comercialização global como commodity ambiental, como mercadoria, graças aos cenários de escassez quali-quantitativa de água doce em algumas partes do planeta, reflexos da ação humana degradante sobre os mananciais e o clima. 
Nesse sentido, a problemática que se emerge nessa pesquisa é: de que forma caracterizar o rio Amazonas como sujeito de direitos e como proteger este bem ambiental assegurando-Ihe a salubridade e qualidade de seus recursos sustentáveis?

Sob a justificativa do desenvolvimento sustentável da Pan-Amazônia, a visão antropocêntrica de exploração dos recursos naturais disponíveis tem prevalecido, com aval dos Estados-Membros do Tratado de Cooperação Amazônica (TCA), apesar da existência de normas jurídicas internacionais que tratam da proteção do meio ambiente. A natureza é considerada um objeto constituído por vastos recursos que devem ser usufruídos prioritariamente pelas presentes gerações e, se possível, garantidos às futuras gerações.

A grande questão é, que historicamente, os lucros auferidos nas atividades degradadoras do meio ambiente da região sequer têm proporcionado a melhoria da qualidade de vida dos seus habitantes. Na verdade, a própria natureza e a Bacia Amazônica, têm sofrido os efeitos danosos do monopólio de alguns, que tem na exploração dos bens ambientais a fonte de suas fortunas e lucros e que promovem com suas ações, ao invés do desenvolvimento regional, o empobrecimento dos povos amazônidas.

Nesse sentido, para combater a degradação ambiental no planeta, as comissões de Direitos Humanos para um ambiente saudável, contam com a ativa participação e construção de um movimento legal e cultural que tem se espalhado por vários países: o reconhecimento dos Direitos da Natureza.

Pessoas, comunidades, tribunais e até mesmo governos de alguns países têm constatado a necessidade de transformação do relacionamento "humanidade $X$ mundo natural", defendendo que a natureza, rios, ecossistemas e espécies ameaçadas têm direitos que devem ser reconhecidos, respeitados e protegidos.

Neste cenário, os Direitos da Natureza mostram-se como alternativa jurídica, a ser considerada, para tutelar o bem-viver do rio Amazonas e suas águas transnacionais compartilhadas, como entidade natural que existe como parte da "Mãe Terra", constituindo-se em elemento cultural, natural e social fundamental a vida na Amazônia. 
Dessa forma, o objetivo dessa pesquisa é o de analisar a legislação ambiental vigente e os novos movimentos de proteção e reconhecimento dos Direitos da Natureza, no sentido de se buscar o equilíbrio entre a exploração dos recursos naturais e os direitos que esses bens ambientais possuem, de existirem com dignidade e com salubridade. A pesquisa se justifica, tendo em vista a necessidade que esses bens possuem de viver e não apenas de sobreviver, uma vez que os seres humanos não conseguirão ter qualidade de vida no planeta, sem a salubridade desses recursos.

A metodologia a ser utilizada nessa pesquisa é a do método dedutivo. Quanto aos meios, utilizar-se-á a pesquisa bibliográfica com uso da legislação, doutrina e decisões judiciais; quanto aos fins, a pesquisa será qualitativa.

\section{RIO AMAZONAS E SUAS ÁGUAS COMPARTILHADAS}

A bacia hidrográfica do rio Amazonas é transnacional e seus afluentes constituem-se em um objeto natural fundamental à harmonia "homem-natureza" no ambiente Amazônico. Suas águas comandam a vida dos seres que compartilham a existência peculiar nessa bela e frágil região.

Segundo Pozzetti e Nascimento (2017, p. 236), "Sem água não há vida e, como a divisão das principais reservas (superficiais e subterrâneas) estão dispostas de forma desigual no planeta, a água se constitui em um bem ambiental com valor econômico estratégico, devendo os Estados realizarem esforços mais contundentes para que esse recurso seja viabilizado a todos.

Desde a descoberta do rio amazonas, pelos colonizadores espanhóis, até os dias atuais, suas águas têm sido utilizadas com fins econômicos pela humanidade, de forma desarrozoada e degradadora, impactando as relações socioambientais que com ele se formam. Entretanto, antes de os espanhóis na região chegarem, o rio Amazonas sempre foi sinônimo de vida, de harmonia e um "sujeito de direitos", afinal era respeitado pelos povos ancestrais que lá viviam e cuidavam de suas águas, para 
que lhes desse o sustento e compartilhasse "vivamente" da vida sustentável destes povos.

A relevância estratégia deste rio internacional, para os países que compõem a Pan-Amazônia (Colômbia, Peru, Venezuela, Equador, Bolívia, Guiana, Suriname e Brasil) é materializada na existência de normas jurídicas internacionais, como o TCA que apesar de tratar do uso racional de suas águas e de incentivar a livre navegação, traz, mesmo que restritivamente, uma abordagem ecocêntrica.

Neste sentido Pozzetti e Nascimento (2017, P. 236) esclarecem a importância da 'natureza amazônica':

Importante destacar que a Amazônia é uma das principais reservas de água doce do planeta, carecendo da iniciativa e efetividade dos países amazônicos em implementar ações diretivas, de forma conjunta, em prol do Desenvolvimento Sustentável e da conservação dos recursos hídricos da Bacia Amazônica, como elemento transformador da sociedade amazônica

Esta visão, no contexto atual de reconhecimento de Direitos da Natureza, pode vir a proporcionar às comunidades, que gozam de uma intimidade ancestral e cultural com o rio Amazonas, a capacidade de defendê-lo ao ponto de provocar a ação dos Estados-Membros do TCA (Tratado de cooperação Amazônica) na proteção, conservação e restauração das águas amazônicas compartilhadas, que o constituem um objeto natural de valor imensurável, um sujeito de direitos.

\subsection{A REPERCUSSÃO GEOPOLÍTICA DO DESCOBRIMENTO DO RIO AMAZONAS}

O rio Amazonas foi descoberto na época das grandes navegações, quando a expedição espanhola do navegador Vicente Yánez Pinzón, pelo acaso de uma tempestade, teve sua rota indiana alterada, deparando-se com a foz do Rio, conforme retrata Bueno (2016, p. 18-19):

[...] Pela primeira vez na história, os europeus deparavam com o fenômeno que os indígenas chamavam de pororoca ('estrondo', em Tupi-Guarani). Era o majestoso encontro das águas do rio Amazonas com as águas do oceano Atlântico. Vencendo a maré e balançando sobre ondas de quase dois metros, 


\begin{abstract}
Pinzón seguiu em frente e logo chegou à imensa foz de um rio, 'uma boca que saía no mar 15 léguas (cerca de 90 quilômetros), com grandíssimo ímpeto'. Os espanhóis concluíram que um curso d'água tão monumental só poderia 'nascer em vastos montes' e que necessariamente precisaria percorrer uma enorme distância antes de se tornar poderoso a ponto de 'adoçar' o mar [...] Aquele 'mar doce' estava coalhado de ilhas - algumas enormes; todas 'felizes pela fertilidade do solo'; a maioria 'habitada de gente mansa e sociável, mas pouco úteis para os nossos porque não possuem produtos desejáveis, a saber: ouro e pedrarias. A frota de Pinzón estava na baía de Marajó. Os nativos chamavam a região de Mariatambal. Pinzón manteve o nome, mas batizou aquele imenso curso d'água de Santa Maria de la Mar Dulce. Tinha acabado de descobrir o maior rio do planeta - o mesmo que, 40 anos mais tarde, seria chamado de Amazonas pelo primeiro explorador que o navegou da nascente à foz, o também espanhol Francisco de Orellana.
\end{abstract}

Os relatos do referido historiador confirmam o controle da Coroa Espanhola sobre a foz do rio Amazonas, a exploração inicial do seu curso e a imediata interação com comunidades indígenas, que até então, gozavam de uma harmoniosa existência com a natureza descoberta, abruptamente monopolizada e explorada pelo colonizador europeu. Bueno (2016, p. 19) continua detalhando a expedição:

\begin{abstract}
Pinzón decidiu explorar o interior da região, que julgava ser 'a Índia além do Ganges, nas proximidades da grande cidade de Catai (a China)'. Seus navios subiram o curso do rio imenso, avançando contra a corrente e percorrendo cerca de 50 léguas (aproximadamente 300 quilômetros) com muita dificuldade. As margens eram densamente habitadas e repletas de aldeias. Havia árvores tão grandes 'que um cordão de 16 homens unidos pelas mãos não era capaz de abraçá-las'. Os animais eram todos desconhecidos e pareciam monstruosos. Um deles, um enorme sariguê (espécie de gambá), foi levado para a Espanha, aonde chegou morto, mas seu corpo, 'bem conservado, causou a admiração de quantos o viram'.
\end{abstract}

A descoberta "completa" do rio Amazonas, dos Andes à foz, no Oceano Atlântico, remonta ao também espanhol Francisco de Orellana, a quem coube confirmar o reconhecimento geopolítico de que as terras amazônicas descobertas se encontravam dentro dos limites da Espanha estabelecidos no Tratado de Tordesilhas, firmado com Portugal, conforme retrata Ribeiro (2005, p. 28-30):

A Amazônia interior somente seria conhecida pelos europeus, através da expedição de Francisco de Orellana que percorreu o rio Amazonas da nascente a foz, entre fevereiro de 1541 e agosto de 1542 [...] As dificuldades impostas aos viajantes pela natureza, porém, foram muito grandes: sofreram 


\begin{abstract}
um terremoto que dizimou grande parte da expedição; subindo a cordilheira andina, sob um frio arrasador e chuvas constantes, viram-se na contingência de deixar a maior parte dos suprimentos que levavam [...] Enfim, após 10 meses de viagem, conseguiram chegar ao rio Coca [...] Orellana capitaneava a expedição com cinquenta e quatro tripulantes, entre os quais o dominicano Frei Gaspar de Carvajal que se tornou o responsável pelo relato da viagem. Chegaram à confluência do rio Coca com o Napo [...] A expedição de Orellana prosseguiu pelo Napo, até chegar ao eixo do 'Grande Rio' ou 'Paranauaçu', como era chamado pelos povos indígenas aquele que seria depois denominado por Orellana como 'Rio das Amazonas'. Continuou navegando com o apoio das populações indígenas, tendo chegado a 3 de junho de 1542 ao rio Negro, nome dado pelo próprio Orellana, quando deparou com o encontro de suas águas com as do Amazonas. Seu contato com as populações indígenas era quase sempre violento, matando e torturando os índios para tomar os suprimentos de que necessitava; muitas vezes, porém fez-se amigo dos indígenas, deles obtendo todo o apoio de que necessitava [...] A 24 de agosto de 1542, a expedição deixou o Amazonas e, enfrentando grandes dificuldades, voltou para a Espanha.
\end{abstract}

Para Souza (1994, p. 29): “[...] a revelação da Amazônia foi um verdadeiro impacto para os europeus. Uma verdadeira colisão cultural, racial e social, que, como em toda a América Latina, provocou as mesmas contradições que se repetiram ao longo do caminho da empresa desbravadora".

Assim, o referido feito do colonizador espanhol impactou o futuro da Amazônia, com o inicial reconhecimento do domínio territorial espanhol e com o despertar dos interesses monopolistas e exploratórios de outros povos europeus, em especial dos portugueses, que lutaram pela posse de suas riquezas e de seu território, domínio este que foi consolidado com o controle do rio Amazonas.

\title{
2.2 O RIO AMAZONAS E SUAS ÁGUAS TRANSNACIONAIS COMPARTILHADAS QUE COMANDAM À VIDA
}

O rio Amazonas é o principal curso d'água internacional da bacia hidrográfica transfronteiriça amazônica, cuja a nascente localiza-se nos Andes peruanos e a foz no litoral atlântico brasileiro. Segundo Nascimento (2015, p.3): A Bacia Amazônica, a maior bacia hidrográfica do mundo, abrange cerca de
40 por cento da América do Sul que, em média, na estação de seca, 110 mil
quilômetros quadrados de terra são cobertos de água. Na estação chuvosa,
a área inundada da Bacia Amazônica sobe para 350 mil quilômetros 
quadrados. O volume de água descarregado pelo Amazonas para o Oceano Atlântico é de até 300 mil metros cúbicos por segundo na estação chuvosa. O rio Amazonas é responsável por cerca de $20 \%$ do volume total de água doce que entra no oceano, a qual corresponde a cerca de 1/5 da descarga total de todos os rios do mundo. [...] Trata-se de uma bacia transfronteiriça que se estende por oito países, Bolívia, Peru, Equador, Colômbia, Brasil, Venezuela, Guiana e Suriname, que partilham os múltiplos usos dos recursos hídricos amazônicos e a responsabilidade para garantir água segura e disponível em quantidades suficientes para a sua finalidade.

A abundância das águas amazônicas compartilhadas é uma realidade com a qual as populações tradicionais $e$ as comunidades indígenas convivem harmonicamente e ancestralmente há séculos. Suas existências nas margens do "grande rio" são influenciadas pela relação com a biodiversidade que é essencial à sobrevivência na e da Floresta Amazônica. Na bacia transfronteiriça amazônica, os rios comandam a vida, afinal a interação homem-natureza se realiza não simplesmente através do uso da água como produto, mas no ser água e fazer parte dos rios, que fluem e alimentam a si próprio e sustentam caboclos, ribeirinhos, quilombolas, pescadores e índios em seu leito.

As populações tradicionais e as comunidades indígenas da Amazônia tem um grande conhecimento sobre rios, igarapés e lagos e sobre os seres que neles habitam, para Diegues (2007, p. 14-15):

O conhecimento tradicional desses povos se relaciona com inúmeros aspectos da vida dos rios e suas relações com a floresta, dos tipos e hábitos dos peixes, como migração, alimentação, época e lugares de desova dos cardumes, etc. Desenvolveram também inúmeras técnicas de captura como armadilhas fixas de baixo impacto sobre os cardumes. Homens e mulheres se relacionam com a água de modo diferenciado. Enquanto a maioria das tarefas extrativistas florestais (produção de borracha, coleta de castanha e outras frutas), a pesca e caça nos rios e igarapés, a preparação do terreno da várzea para a agricultura é realizada por homens, as mulheres e crianças são responsáveis pela retirada da água para o uso doméstico e por algumas tarefas agrícolas (plantio e colheita na várzea), e artesanais. Os igarapés também são muito usados para atividades de lazer. As moradias também são construídas em palafitas, adaptadas aos períodos cíclicos de enchente e vazante que, em parte, são determinantes no estilo de vida dessas populações que vivem dos rios e das florestas. Em rios como o Solimões, as chuvas intensas se prolongam de novembro a janeiro quando aumenta os índices de doenças tropicais como a malária, a hepatite. O contato entre as comunidades só pode ser feito por barco, pois os caminhos ficam inundados. Já a vazante vai de abril a julho, sendo caracterizada por um período de insetos e pragas. A estiagem se estende de agosto a outubro. Nesse período 


\begin{abstract}
faz- se o plantio nas várzeas ou terras molhadas, intensifica-se a pesca. Os caminhos entre as casas voltam a ser transitáveis, intensificando-se a vida social. Entre os caboclos ribeirinhos existem lendas sobre a Mãe d'água para a qual é necessário se dar presentes para que a pesca seja abundante, sobre a lara, o Boto, etc.. Outros mitos narram as relações amistosas entre os seres dos rios e das matas que garantem a vida dos homens que, por sua vez, não devem perturbá-las. Esse rico universo simbólico é fundamental para garantir a identidade do grupo e sua relação com as águas que são consideradas parte integrante do seu território ancestral.
\end{abstract}

Tocantins (2000, p. 277) reforça que: "O homem e o rio são os dois mais ativos agentes da geografia humana da Amazônia. O rio enchendo a vida do homem de motivações psicológicas, o rio imprimindo à sociedade rumos e tendências, criando tipos característicos na vida regional".

Assim, o rio Amazonas e suas águas compartilhadas através de suas nascentes, de seus tributários, da bacia hidrográfica transnacional integram e organizam vidas, elementos naturais como solo, árvores, peixes, animais, aves, ar, água com as pessoas, em um ambiente onde todos se relacionam e dele são parte, constituindo assim um universo simbólico que os identifica com as águas e como amazônicos.

Apesar da vida com abundância hídrica ser uma realidade na região, há um paradoxo amazônico relacionado ao acesso à água, segundo Nascimento (2015, p. 3):

\footnotetext{
Apesar da imensa reserva de água, o consumo humano é restrito devido, basicamente, à contaminação urbana causada por falta de saneamento básico e a entrada de diferentes fontes de poluição, como resultado das atividades socioeconômicas (mineração de metálicos e não metálicos, combustíveis fósseis, agroindústria).
}

Reforçando o desequilíbrio do meio ambiente e os efeitos sobre a vida do homem e da natureza, o relatório GEO Brasil sobre Recursos Hídricos elaborado com o apoio do Programa das Nações Unidas para o Meio Ambiente (PNUMA) pela Agência Nacional de Águas - ANA (2007, p. 30) destaca que:

A ação antrópica, principalmente a conversão de mais de $600.000 \mathrm{~km} 2$ de florestas tropicais em pastagens e culturas agrícolas, associada a mudanças 
regionais e globais têm provocado alterações no clima e na hidrologia da Amazônia. As alterações estão relacionadas, entre outros, à aceleração do degelo dos Andes e à ocorrência de fenômenos de alteração da temperatura do mar (conhecidos como El Niño e La Niña). Este fenômeno, registrado em 2005, alterou as massas de ar úmidas da Amazônia e resultou numa seca de extrema gravidade, que afetou mais de 167 mil habitantes somente no Estado do Amazonas.

Ou seja, a ação antrópica alicerçada na valorização econômica dos bens ambientais que compõem a natureza tem provocado e agravado o desequilíbrio socioambiental amazônico ao longo dos séculos. No descobrimento do rio Amazonas pelos europeus houve uma grave degradação social das comunidades indígenas que habitavam a região. Hoje, ações degradantes e poluidoras, como o desmatamento, a mineração, a exploração de petróleo, a construção de barragens para geração de energia, a ocupação urbana desordenada e a falta de saneamento impactam diretamente a vida do Rio, a qualidade de suas águas e a sobrevivência dos seres humanos que dele são parte, culturalmente ou ancestralmente.

\subsection{O RIO INTERNACIONAL E SUA RELEVÂNCIA GEOPOLÍTICA NA PAN- AMAZÔNIA}

A integridade do rio Amazonas e a consequente proteção, gerenciamento e conservação de suas águas transfronteiriças compartilhadas perpassa pelo Direito Internacional Público. Os conceitos jurídicos relacionados estão nas Regras de Helsinque (ILA, 1966) e na Convenção da Nações Unidas de Nova lorque sobre o Direito dos usos não navegáveis dos cursos de água internacionais (ONU, 1997).

O art. 2ำ das Convenção de Helsinque de 1966, define bacia de drenagem internacional, como a: "[...] área geográfica que se estende por dois ou mais Estados determinados pelos limites hidrológicos do sistema de águas, incluindo águas superficiais e subterrâneas, que fluem para um terminal comum" (ILA, 1966, tradução nossa).

Já o conceito de curso de água internacional, consta do art. 2ํ da Convenção de Nova lorque, no caso: "[...] é um curso de água cujas partes estão situadas em estados diferentes" (ONU, 1997, tradução nossa). 
A soberania de cada Estado ribeirinho é absoluta nos respectivos territórios, o que possibilita aos mesmos disporem com liberalidade das águas transfronteiriças compartilhadas, orientados apenas pela aplicação dos princípios comuns, de ambas as normas, no caso o uso equitativo e razoável do rio (previsto no art. 5 das Regras de Helsinque/1966 e no art. $6^{\circ}$ da Convenção de Nova lorque/1997) e o compromisso de não causar danos significativos aos outros Estados (constante no art. 5을 Regras de Helsinque/1966 e no art. $7^{\circ}$ da Convenção de Nova lorque/1997).

Importante destacar a origem e as características do rio Amazonas, detalhadas no relatório do Projeto GEF - Amazonas, que evidenciam a transnacionalidade das águas deste bem ambiental e que justificam os valores atribuídos ancestralmente e culturalmente pelas comunidades que dele são parte:

O rio Amazonas nasce no vale de Apacheta, na montanha de Mismi, cordilheira de Shila, Departamento de Arequipa, Peru, a uma altitude de 5.597 m. As águas de degelo fluem em direção ao rio Apurímac, tributário do Ucayali, que finalmente se une ao Marañón para formar o canal principal do rio Amazonas. Assim, a confluência entre o rios Apurímac e Ucayali é a transição do percurso do rio da região andina para a planície aluvial inundável e suavemente ondulada. $O$ rio segue seu percurso na fronteira colombo peruana, na fronteira tríplice incluindo-se o Brasil, onde recebe as águas do rio Negro. Nessa região da confluência é marcante o contraste entre as águas ao longo de 230 quilômetros, devido a baixa velocidade das correntes fluviais. Da mesma forma, observa-se o contraste de águas na confluência das as "águas claras" do rio Tapajós com as "águas brancas" do Amazonas [...] Nos países andinos o Amazonas é denominado Marañón, ao entrar no Brasil é chamado de rio Solimões e ao receber as águas do rio Negro, no Estado do Amazonas, passa a ser chamado de rio Amazonas. No seu percurso de $6.992,06 \mathrm{Km}$ e largura média de $5,0 \mathrm{Km}$ até a desembocadura no Atlântico, o rio tem tributários, em grande parte, influenciados pelos processos de cheia e vazante, oriundos de sete países, formando a maior bacia hidrográfica do planeta, com uma extensão estimada em 6.100,00 $\mathrm{Km}^{2}$ (NASCIMENTO, 2015, p. 21-22).

Neste cenário, o Tratado de Cooperação Amazônica (TCA), de 1978, foi firmado para regular a relação multilateral entre os Estados-Membros que compõem a bacia transfronteiriça e a floresta amazônica em um espaço consolidado, a PanAmazônia, conforme destaca Ribeiro (2005, p. 203): "[...] os países amazônicos optaram por uma definição geopolítica para indicar as áreas que são objeto do Tratado 
de Cooperação Amazônica". A relevância do referido Tratado para os países amazônicos signatários é reforçada por Nascimento e Pozzetti (2017, p. 125 - 126):

\begin{abstract}
O pioneirismo dos seus signatários, sob a liderança do Brasil, fez com que o referido Tratado inovasse em alguns assuntos, à época ainda pouco explorados, como a temática ambiental, em especial no estímulo a cooperação e na previsão de uso racional dos recursos hídricos, algo na oportunidade e, quiçá ainda hoje, paradoxal de se pensar em face da abundância de água doce, mas que já merecia a devida atenção, principalmente, por causa da importância econômica e social dos rios para a região. Contudo, sob o prisma da manutenção das soberanias de cada país no uso dos recursos ambientais em suas fronteiras, o grande destaque, se prestou à exploração econômica das vastas riquezas, em especial ouro, energia, petróleo e gás, e a ocupação desordenada dos territórios, em detrimento da conservação da floresta e dos ecossistemas conexos, bem como da qualidade de vida das populações que habitam estes rincões.
\end{abstract}

Assim, na análise dos arts. IV, V e XVI do TCA, se percebe, de forma explícita, a limitação das soberanias dos países da Pan-Amazônia pelo Direito Internacional, no caso, pelos princípios de uso equitativo e razoável do rio e do compromisso de não causar danos significativos aos outros Estados ribeirinhos (BRASIL, 1980).

O TCA, conforme seu art. III, segue a regra geral do Direito Internacional Público ao tratar os rios amazônicos como objetos, passíveis de exploração econômica e do uso de suas águas, com a ressalva de que o equilíbrio entre sua conservação e o desenvolvimento regional seja garantido (BRASIL, 1980).

Na prática, o Tratado reconheceu há mais de 40 (quarenta) anos, que os rios amazônicos têm funções sociais e relacionais que são capazes de criar laços de cooperação entre os Estados-Membros e fomentar o desenvolvimento social, econômico e ambiental das comunidades que vivem dos e nos rios, conforme referenciadas nos arts. V e VI do TCA (BRASIL, 1980), in verbis:

ARTIGO V - Tendo em vista a importância e multiplicidade de funções que os rios amazônicos desempenham no processo de desenvolvimento econômico social da região, as Partes Contratantes procurarão envidar esforços com vistas à utilização racional dos recursos hídricos. ARTIGO VI - Com o objetivo de que os rios amazônicos constituam um vínculo eficaz de comunicação entre as Partes e com o Oceano Atlântico, os Estados ribeirinhos interessados num determinado problema que afete a navegação livre e desimpedida empreenderão, conforme for o caso, ações racionais, bilaterais ou multilaterais para o melhoramento e habitação dessas vias navegáveis. 
Certos aspectos constantes dos arts. XIII e XIV do TCA (BRASIL, 1980) evidenciam ainda, a tutela da relação das pessoas com a natureza, o que demonstra o pioneirismo e atualidade do seu texto, por prever a importância da conservação das riquezas da vida ancestral amazônica e, mesmo que implicitamente, o valor atribuído pelas comunidades indígenas ao rio Amazonas, in verbis:

\begin{abstract}
ARTIGO XIII - As Partes Contratantes cooperarão para incrementar as correntes turísticas, nacionais e de terceiros países, em seus respectivos territórios amazônicos, sem prejuízo das disposições nacionais de proteção às culturas indígenas e aos recursos naturais. ARTIGO XIV - As Partes Contratantes cooperação no sentido de lograr a eficácia das medidas que se adotem para a conservação das riquezas etnológicas e arqueológicas da área amazônica.
\end{abstract}

Neste sentido, sobre a relação "vida-homem-natureza", Shiva (2006, p. 160161) destaca que:

\begin{abstract}
Oceanos, rios e outros corpos compostos de água exerceram um papel importante como metáforas de nossas relações com o planeta. Diferentes culturas têm diferentes sistemas de valores por meio dos quais 0 comportamento ético, ecológico e econômico da sociedade é guiado e moldado. Da mesma forma, a ideia de que a vida é sagrada coloca um alto valor nos sistemas vivos e previne sua mercantilização. A proteção de recursos naturais não pode ser assegurada apenas pela lógica de mercado. Ela exige uma recuperação do sagrado e uma recuperação dos bens comuns [...] Águas sagradas nos levam além do mercado para um mundo carregado com mitos e histórias, crenças e devoção, cultura e celebração. Este é o mundo que nos permite salvar e compartilhar a água e converter escassez em abundância.
\end{abstract}

Por todo o exposto, se pode verificar que há o reconhecimento, mesmo que restrito, no TCA da natureza como um ser sagrado, do qual depende a vida, a integridade e preservação da Amazônia; não apenas como um simples conjunto de bens ambientais passíveis de serem valorados economicamente.

Tal percepção, fundada na cultura ancestral dos povos tradicionais e das comunidades indígenas, tem influenciado a elaboração de legislações e de decisões constitucionais nos países da Pan-Amazônia, de forma que a natureza tem adquirido a condição de entidade, dotada de direitos. 
Neste sentido, o reconhecimento da personalidade jurídica do rio Amazonas seria algo fundamental à conservação da bacia transfronteiriça amazônica, por possibilitar que pessoas que vivem na região atuem como partes legítimas, capazes de vir a provocar a prestação jurisdicional frente aos riscos inerentes a ação exploratória das águas amazônicas, para que o Rio assim possa comandar a vida na Pan-Amazônia, sem paradoxos e evitando conflitos futuros por suas águas, hoje, ainda compartilhadas.

\section{OS DIREITOS DA NATUREZA - PACHAMAMA, "MÃE TERRA"}

O colapso climático global, diretamente relacionado aos impactos da exploração da natureza pela humanidade, é uma realidade da qual vários países têm, há algum tempo, buscado formas conjuntas de enfrentar.

Desde a Convenção das Nações Unidas sobre Meio Ambiente Humano de Estocolmo (1972), da Conferência das Nações Unidas para o Meio Ambiente e o Desenvolvimento do Rio de Janeiro (1992) e da Convenção-Quadro das Nações Unidas sobre Mudança do Clima (1992), perpassando pelo Protocolo de Kyoto (1998) e pelo Acordo de Paris (2015), o Direito Internacional do Meio Ambiente se consolidou em diversos Tratados, que estabeleceram princípios jurídicos de tutela do meio ambiente, metas equitativas para redução de emissões de gases de efeito estufa (GEE) e estímulos ao desenvolvimento sustentável.

Todavia, em que pese as ações dos Estados signatários dos referidos instrumentos jurídicos internacionais, os efeitos colaterais da ação antrópica degradante e irresponsável sobre o meio ambiente têm sido percebidos por todos. Isto, tem despertado nas pessoas e nas organizações não-governamentais o interesse de agir e contribuir ativamente com ações locais, regionais e globais de preservação dos ecossistemas dos quais somos parte.

Esta atitude tem proporcionado uma transformação da relação das pessoas com a natureza, não mais considerada um simples conjunto de coisas ou objetos ou 
propriedades dotadas de valor econômico ou bens jurídicos ou bens ambientais que devam ser tutelados pelo Direito Internacional do Meio Ambiente.

A natureza e a humanidade dependem uma da outra, são um só, suas existências se relacionam e são compartilhadas, se o meio ambiente é degradado, a vida no planeta é afetada, todos sofrem e tem suas sobrevivências colocadas em risco.

Assim, os Direitos da Natureza, dos rios, dos ecossistemas, da biodiversidade, dos animais, da humanidade, da criação de Deus, que tudo criou para a convivência e existência harmônica e em paz, têm adquirido força normativa, através do reconhecimento constitucional e jurisdicional de que o meio ambiente, inclusive cada bem ambiental, deve ser tutelado, pela sua unicidade, como um ente, capaz de provocar a ação jurisdicional, através de qualquer ser humano, em favor de sua integridade e conservação.

\subsection{O RECONHECIMENTO CONSTITUCIONAL DOS DIREITOS DA NATUREZA}

Para abordar a origem dos Direitos da Natureza é fundamental tratar das definições etimológicas e semânticas das palavras Direito e Natureza. O vocábulo Direito tem origem no adjetivo latino directus, que ilustra a qualidade de estar conforme a reta, a lei, ser lei, a ciência que estuda as leis (NADER, 2008, p. 75). Já a palavra Natureza origina do latim natura, aquilo que surge, nasce, o mundo natural, ambiente onde a humanidade existe (DICIO, 2019).

O Direito tem origem na sociedade, na relação do homem com os acontecimentos ao seu redor. Este, para o enfrentamento dos problemas resultantes da ação humana desarrozoada sobre o meio ambiente, como objeto do monopólio de alguns homens, se ampara nas normas jurídicas, nos costumes, nas decisões judiciais e nos atos-regras, como estruturas do poder legislativo, social, judicial e negocial (REALE, 1976, p. 141). A fonte material do Direito segundo Reale (1976, p. 140) é: "[...] o estudo filosófico ou sociológico dos motivos éticos ou dos fatos que condicionam o aparecimento e as transformações das regras do Direito". 
Desta feita, os Direitos da Natureza são frutos da resposta à ação crítica e ética da humanidade, já realidade em alguns países, como mecanismo corajoso de enfrentamento aos fatos causadores e/ou agravadores do risco à extinção da vida no planeta.

A sociedade não pode permanecer à mercê do atual sistema de poder, centrado na dimensão econômica. A valorização do capital proveniente do uso da natureza como recurso essencial à um desenvolvimento desigual e devastador, desconsiderando as necessidades socioambientais, não pode prevalecer. É urgente, como está ocorrendo, a adoção de uma dimensão ecológica, conforme destaca Boyd (2017, p. 350, tradução nossa):

\begin{abstract}
Felizmente, existem provas por todo o mundo que pessoas, legislaturas e Tribunais estão começando a reconhecer e proteger os direitos de outros membros da comunidade do nosso planeta. As leis estão protegendo os direitos de grandes macacos e cetáceos (baleias, golfinhos e botos). Ações judiciais estão buscando (e em alguns casos ganhando) liberdade para chimpanzés, baleias e outros animais mantidos em cativeiro. As Decisões judiciais estão colocando a sobrevivência de espécies ameaçadas de extinção, acima dos interesses humanos [...] Da Nova Zelândia ao Equador, constituições, leis e juízes estão reconhecendo os direitos dos rios, florestas e ecossistemas.
\end{abstract}

Os Direitos da Natureza têm como base o reconhecimento de que a humanidade e a natureza coexistem, são unos e compartilham no e do meio ambiente, cabendo a normativa jurídica e a hermenêutica fundada nos princípios da proporcionalidade e da precaução, orientar e conduzir o respeito mútuo a este relacionamento para o bem viver de ambos. Neste sentido, Nash (1993, p. 248 - 249, tradução nossa) complementa:

É uma questão de urgência moral, num momento em que as reduções de
populações não humanas e as extinções de espécies estão ocorrendo em um
ritmo apavorante. As fontes naturais para as necessidades e desejos
humanos, que eufemisticamente chamamos de recursos naturais renováveis,
são também uma diversidade surpreendente de formas de vida que lutam por
sustento e espaço na complexa interdependência. Esse duplo status de
outras espécies - tanto como valores instrumentais para a humanidade
quanto valores intrínsecos para si - nos confronta com uma série de dilemas
morais raramente reconhecidos. O significado moral da outra espécie não
pode ser reduzido a instrumentos, recursos ou objetos para as necessidades 
e desejos humanos. Toda a natureza não pode ser definida por propósitos humanos e sujeita a melhorias humanas. A natureza tem sua própria integridade que desafia a arrogância humana e exige respeito e proteção humanos. Em última análise, a integridade da natureza é também a integridade da espécie humana como parte e produto da natureza.

A origem do reconhecimento constitucional da matéria, no mundo, remonta a Constituição da República do Equador de 2008 (CRE/08), que em seu preâmbulo celebra a natureza, a Pacha Mama e decide construir uma nova forma de convivência pública, baseada na diversidade e em harmonia com a natureza para alcançar o bom modo de viver (EQUADOR, 2008). O direito ao meio ambiente saudável é estabelecido no seu art. 14, in verbis:

\begin{abstract}
Art. 14 É reconhecido o direito da população a viver em um ambiente saudável e ecologicamente equilibrado, que garanta a sustentabilidade e o bom viver [...] A conservação ambiental, a proteção dos ecossistemas, a biodiversidade e a integridade do patrimônio genético do país, a prevenção de danos ambientais e a recuperação de espaços naturais degradados são assuntos declarados de interesse público (EQUADOR, 2008, tradução nossa).
\end{abstract}

Os Direitos da Natureza são reconhecidos nos arts. 71, 72, 73 e 74, da CRE/08, em 4 (quatro) aspectos: no respeito integral à existência e a manutenção e regeneração dos ciclos de vida; no direito de restauração; no dever de tutela do Estado sobre as espécies, aos ecossistemas e aos ciclos naturais; e no benefício social do meio ambiente para o bem viver.

Cabe destacar, um dos pontos inovadores da referida Carta Constitucional, no qual se reconhece a legitimidade de todos, erga omnes, de provocação das autoridades públicas em prol dos referidos Direitos da Natureza, conforme o art. 71, da CRE/08, in verbis:

Art. 71 A natureza, ou Pacha Mama, onde a vida é reproduzida e ocorre, tem direito ao respeito integral por sua existência e pela manutenção e regeneração de seus ciclos de vida, estrutura, funções e processos evolutivos. Todas as pessoas, comunidades, povos e nações podem convocar as autoridades públicas para fazer valer os direitos da natureza. Para fazer cumprir e interpretar esses direitos, os princípios estabelecidos na Constituição devem ser observados, conforme apropriado. O Estado dará incentivos às pessoas físicas e jurídicas e às comunidades para proteger a 
natureza e promover o respeito por todos os elementos que compõem um ecossistema (EQUADOR, 2008, tradução nossa).

Outro marco normativo sobre os Direitos da Natureza, que importa citar, é o reconhecimento constitucional pela Bolívia dos Direitos da "Mãe Terra", com caráter de interesse público coletivo, cujos direitos inclusive prevalecem sobre os dos bolivianos.

Estes direitos coletivos são regulados pela Lei no 71/2010, que no art. 3o, conceitua "Mãe Terra" como: "[...] um sistema vivo dinâmico que compreende uma comunidade indivisível de todos os sistemas vivos e organismos vivos, interrelacionados, interdependentes e complementares, que compartilham um destino comum" (BOLÍVIA, 2010, tradução nossa).

Os referidos direitos coletivos, para a vida, à diversidade da vida, à água, para limpar o ar, equilibrar, para a restauração e a vida livre de poluição estão detalhados no art. $7^{\circ}$, da Lei $\mathrm{n}^{\circ} 71 / 2010$, in verbis:

Art. $7^{\circ}[\ldots]$ 1. Para a vida: $O$ direito de manter a integridade dos sistemas vivos e processos naturais que os sustentam, e as capacidades e condições para a regeneração. 2. À diversidade da vida: É o direito à preservação da diferenciação e variedade de seres que compõem a Mãe Terra, sem ser geneticamente alterado ou estruturalmente modificado de forma artificial, para que sua existência, funcionamento ou potencial futuro sejam ameaçados. 3. À água: O direito de preservar a funcionalidade do ciclo da água, sua existência na quantidade e qualidade necessárias para sustentar os sistemas vivos e sua proteção contra a poluição para a reprodução da vida da Mãe Terra e de todos os seus componentes. 4. Para limpar o ar: O direito de preservar a qualidade e a composição do ar para sustentar os sistemas vivos e sua proteção contra a poluição, para a reprodução da vida da Mãe Terra e de todos os seus componentes. 5. Equilibrar: $\mathrm{O}$ direito à manutenção ou restauração da inter-relação, interdependência, complementaridade e funcionalidade dos componentes da Mãe Terra de maneira equilibrada para a continuação de seus ciclos e reprodução de seus processos vitais. 6. Para a restauração: $O$ direito à restauração oportuna e eficaz de sistemas vivos afetados por atividades humanas direta ou indiretamente. 7. À vida livre de poluição: o direito à preservação de qualquer componente da Mãe Terra da contaminação, bem como resíduos tóxicos e radioativos gerados por atividades humanas (BOLÍVIA, 2010, tradução nossa).

Por derradeiro, um dos mais recentes reconhecimentos constitucionais dos Direitos da Natureza, como uma entidade coletiva sujeita a direitos, ocorreu no 
México, que no art. 18, $\S \S 2^{\circ}$ e $3^{\circ}$, da Constituição Política da Cidade do México de 2017 assim estabeleceu:

Art. $18[\ldots] \S 2^{\circ}$. O direito à preservação e proteção da natureza será garantido pelas autoridades da Cidade do México no âmbito de sua competência, promovendo sempre a participação cidadã na matéria. § $3^{\circ}$. A fim de cumprir esta disposição, será emitida uma lei secundária que terá como objetivo reconhecer e regulamentar a proteção mais ampla dos direitos da natureza conformados por todos os seus ecossistemas e espécies como uma entidade coletiva sujeita a direitos (México, 2017, tradução nossa).

Assim, essas normas constitucionais materializam a influência do interesse coletivo sobre alguns Estados, que tem tolerado a transformação ecológica e ética do relacionamento homem-natureza, possibilitando a construção de uma nova relação jurídica fundada nos interesses sociais e naturais recíprocos de sobreviverem ao risco da extinção e usufruírem de uma vida salutar conjuntamente.

\subsection{RIOS COMO PESSOAS JURÍDICAS: É POSSÍVEL?}

A natureza tem sido degradada pelo uso desarrazoado da humanidade. O colapso climático já ocasiona desastres ambientais que atingem diretamente a sociedade, muitas pessoas têm enfrentado circunstâncias de intenso sofrimento. Ao perderem suas famílias e perspectivas de vida por ação da seca, de terremotos, de furacões, de tsunamis, estas têm vagado para locais distantes, na esperança da sobrevivência e de um recomeço, em busca de oportunidades que lhes deem dignidade e qualidade de vida.

Neste cenário, surge a necessidade de se tutelar a natureza, não como um bem jurídico dotado de valor econômico, mas considerá-la dotada de personalidade jurídica própria, como entidade, seja como um todo ou considerada individualmente pelos bens ambientais que a constituem, por sua essencialidade a vida no planeta.

Para Nader (2008, p. 75), o conceito de pessoa jurídica: “[...] é uma construção elaborada pela Ciência do Direito, em decorrência da necessidade social de criação 
de entidades capazes de realizar determinados fins, que não são alcançados normalmente pela atividade individual isolada".

No caso Sierra Club X Morton, julgado na Suprema Corte Americana, o Juiz William O. Douglas afirma que:

O rio, por exemplo, é o símbolo vivo de toda a vida que ele sustenta ou nutre - peixes, insetos aquáticos, pássaros, lontras, pescadores, veados, alces, ursos e todos os outros animais, incluindo o homem, que são dependentes dele ou que o apreciem por sua visão, seu som ou sua vida. O rio tão simples fala pela unidade ecológica da vida que faz parte dela. As pessoas que têm uma relação significativa com esse corpo de água - seja um pescador, um canoísta, um zoólogo ou um madeireiro - devem ser capazes de falar pelos valores que o rio representa e que estão ameaçados de destruição (USSC, 1972, p. 7, tradução nossa).

Assim, há a necessidade do reconhecimento da proteção jurídica à natureza como entidade, com personalidade jurídica própria, pela qual qualquer pessoa poderá postular pelo direito do rio, dos animais, das florestas se manterem conservados no âmbito jurisdicional nacional e internacional. $\mathrm{O}$ fato de um rio ser reconhecido como um ente com direitos, não o iguala a um ser humano, bem como não impede a navegação em suas águas e/ou que um pescador artesanal capture um peixe para alimentar sua família, mas garante ao rio os mesmos direitos que qualquer outra coisa tem no meio ambiente e que mais indivíduos possam vir a ser responsabilizados por condutas degradantes das suas águas. Segundo Shelton (2015, p. 16, tradução nossa):

\begin{abstract}
Se for dado o direito de processar, a pessoa jurídica 'natureza' se tornaria uma das poucas entidades não humanas assim dotadas [...] Aqueles que defendem os direitos das entidades naturais argumentam que permitir que a natureza processe, por si só, significaria que mais indivíduos que anteriormente escaparam à responsabilidade possam enfrentar sanções por seu comportamento destrutivo [...].
\end{abstract}

A lógica que justifica esta importante realidade jurídica, perpassa justamente pelos interesses da coletividade, não alicerçados no uso do rio como um bem ou uma mercadoria, mas para garantir ao rio e aos seres humanos a possibilidade de conviverem e existirem, sem que o rio seja degradado ou que todos sejam extintos. 
Alguns rios no mundo já tiveram suas personalidades como entidades naturais reconhecidas, cabe destacar o rio Whanganui na Nova Zelândia, com base no status legal adquirido através do reconhecimento da entidade ancestral do povo Maori Te Awa Tupua representada fisicamente pelo Te Pou Tupua, um conselho composto por representantes das comunidades indígenas e do governo, nos temos dos arts. 12, 14 e 18 da Lei $n^{0}$ 7/2017, in verbis:

12 Te Awa Tupua é um todo indivisível e vivo, que compreende o rio Whanganui desde as montanhas até o mar, incorporando todos os seus elementos físicos e metafísicos. 14 Te Awa Tupua declarou ser pessoa legal. (1) Te Awa Tupua é uma pessoa coletiva e tem todos os direitos, poderes, deveres e responsabilidades de uma pessoa coletiva. (2) Os direitos, poderes e deveres do Te Awa Tupua devem ser exercidos ou executados, e a responsabilidade pelos seus deveres deve ser assumida, por Te Pou Tupua em nome e em nome do Te Awa Tupua, na forma prevista em esta parte e em Ruruku Whakatupua - Te Mana o Te Awa Tupua. 18 Estabelecimento, propósito e poderes de Te Pou Tupua. (1) O escritório de Te Pou Tupua é estabelecido. (2) O objetivo de Te Pou Tupua é ser o rosto humano de Te Awa Tupua e atuar em nome de Te Awa Tupua. (3) A Te Pou Tupua tem plena capacidade e todos os poderes razoavelmente necessários para alcançar seu objetivo e desempenhar e exercer suas funções, poderes e deveres de acordo com esta Lei (NZL, 2017, tradução nossa).

A Corte Constitucional da República da Colômbia, na sentença T-622/2016 relacionada a ação de tutela coletiva interposta em defesa do rio Atrato e dos direitos fundamentais dos povos tradicionais e comunidades indígenas que vivem em sua bacia hidrográfica, afirmou que:

[...] O maior desafio que o constitucionalismo contemporâneo tem em questões ambientais é conseguir a salvaguarda e proteção efetiva da natureza, das culturas e formas de vida associadas a ela e à biodiversidade, e não pelo simples uso material, genético ou produtivo que estes podem representar para o ser humano, mas porque, sendo uma entidade viva composta de outras formas múltiplas de vida e representações culturais, eles são sujeitos de direitos individualizáveis, o que os torna um novo imperativo de respeito e proteção integral pelos Estados e sociedades. Em suma, somente a partir de uma atitude de profundo respeito e humildade com a natureza, seus membros e sua cultura é possível entrar em relações com eles em termos justos e equitativos, deixando de lado qualquer conceito que se limite apenas ao utilitário, ao econômico ou a eficiência. Em outras palavras: a natureza e o meio ambiente são um elemento transversal da ordem constitucional colombiana. Sua importância está, é claro, na atenção aos seres humanos que a habitam e na necessidade de ter um ambiente saudável para viver uma vida digna e em condições de bem-estar, mas também em 
relação aos outros organismos vivos com os quais o planeta é compartilhado, entendidos como existências dignas de proteção em si mesmas. Trata-se da consciência da interdependência que nos conecta a todos os seres vivos na Terra; isto é, reconhecendo-nos como partes integrantes do ecossistema global - biosfera -, e não de categorias normativas de dominação, exploração simples ou utilidade (CRCC, 2016, p. 42-43, tradução nossa).

E decidiu a citada Corte Constitucional, com base na Constituição do país, nos Tratados Internacionais de tutela do meio ambiente assinados pela Colômbia e nos direitos bioculturais de tutela conjunta e interdependente do homem e da natureza, que:

[...] o rio Atrato é sujeito de direitos que implicam sua proteção, conservação, manutenção e, no caso específico, restauração. Para a aplicação efetiva da presente declaração, o Tribunal decide que o Estado colombiano para exercer a tutela e representação jurídica dos direitos do rio, juntamente com as comunidades étnicas que vivem na bacia do rio Atrato em Chocó; assim, o rio Atrato e sua bacia - doravante - serão representados por um membro das comunidades atuantes e por um delegado do Estado colombiano. Além disso, e a fim de assegurar a proteção, recuperação e conservação adequada do rio, ambas as partes devem projetar e montar uma comissão de guardiões do rio Atrato cuja organização e membros se desenvolverá de acordo com as ordens deste julgamento (CRCC, 2016, p. 139-140, tradução nossa).

A visão de que os seres humanos e a natureza se integram no meio ambiente deve prevalecer e ser fortalecida no mundo, não mais se admite o monopólio do homem sobre o rio, suas águas. Assim, com base em tais iniciativas e na consciência da interpendência que nos conecta a todos os seres vivos no planeta, o rio Amazonas, sua bacia e seus afluentes devem ser reconhecidos como um sujeito de direitos, provavelmente como mecanismo mais ágil, através da provocação dos povos tradicionais e das comunidades indígenas aos Tribunais Constitucionais da PanAmazônia.

Assim, talvez no futuro, uma comissão protetora composta por representantes dos referidos postulantes, com valores culturais e ancestrais relacionados ao Rio, possa representá-lo legalmente garantindo seus direitos de proteção, conservação, manutenção e restauração a cargo dos Estados-Membros do TCA, alicerçados nos seus múltiplos modos de vida expressos na diversidade cultural, nos ecossistemas e na grandiosidade da bacia amazônica. 


\subsection{OS DIREITOS DA NATUREZA NAS NORMAS INTERNACIONAIS}

O Direito Internacional regula a proteção aos recursos naturais em diversas Convenções das Nações Unidas e Tratados multilaterais firmados pelos Estados, em especial a partir da Conferência das Nações Unidas sobre o Meio Ambiente Humano de Estocolmo (1972). Todavia o enfoque que tem prevalecido, até então, pauta-se no uso sustentável da natureza, como propriedade, para o alcance de um desenvolvimento, onde os interesses econômicos soberanos prevalecem sobre os socioambientais.

O impacto no ambiente planetário ocasionado pelas mudanças climáticas exerce forte pressão nos sistemas legais, influenciando na criação de leis nacionais e em decisões judiciais que já têm reconhecido a personalidade jurídica de objetos naturais significativos, que em face desta condição, têm adquirido direitos que os tutelam proativamente, não somente após a degradação. Destacando a valoração da ecologia no âmbito do novo constitucionalismo latino-americano, cabe citar trecho do Acórdão do Supremo Tribunal Federal, que apreciou o Recurso Extraordinário no 835558/SP:

As violações ambientais mais graves recentemente testemunhadas no plano internacional e no Brasil, repercutem de modo devastador na esfera dos direitos humanos e fundamentais de comunidades inteiras. $E$ as graves infrações ambientais podem constituir, a um só tempo, graves violações de direitos humanos, máxime se considerarmos que o núcleo material elementar da dignidade humana 'é composto do mínimo existencial, locução que identifica o conjunto de bens e utilidades básicas para a subsistência física e indispensável ao desfrute da própria liberdade. Aquém daquele patamar, ainda quando haja sobrevivência, não há dignidade' [...] A Ecologia, em suas várias vertentes, reconhece como diretriz principal a urgência no enfrentamento de problemas ambientais reais, que já logram pôr em perigo a própria vida na Terra, no paradigma da sociedade de risco. É que a crise ambiental traduz especial dramaticidade nos problemas que suscita, porquanto ameaçam a viabilidade do continuum das espécies. Já, a interdependência das matrizes que unem as diferentes formas de vida, aliada à constatação de que a alteração de apenas um dos fatores nelas presentes pode produzir consequências significativas em todo o conjunto, reclamam uma linha de coordenação de políticas, segundo a lógica da responsabilidade compartilhada, expressa em regulação internacional centrada no multilateralismo (STF, 2017). 
Assim, tem surgido globalmente, com casos concretos de aplicação no âmbito nacional de diversos países, um sistema jurídico biótico definido por Nash (1993, p. 238, tradução nossa) como: "[...] reivindicações moralmente justificadas ou demandas em nome de organismos não humanos, indivíduos ou agregados (populações e espécies), contra todos os agentes morais pelos interesses vitais ou condições imperativas de bem-estar para os não-humanos". Segundo Mazzuoli (2004, p. 348) à:

[...] medida que os Estados assume compromissos mútuos em convenções internacionais, que diminuem a competência discricionária de cada contratante, eles infringem sua soberania, e isto constitui uma tendência do constitucionalismo contemporâneo, que aponta para a prevalência da perspectiva monista internacionalista para a regência das relações entre direito interno e internacional.

No Direito Internacional, a referida concepção jurídica da natureza, amparada pelos valores culturais e ancestrais atribuídos pelos povos tradicionais e comunidades indígenas aos rios, florestas e biodiversidade presentes nos respectivos territórios, pode ser verificada na Convenção no 169/1989, da Organização Internacional do Trabalho sobre povos indígenas e tribais, em especial, no art. 13, in verbis:

[...] os governos deverão respeitar a importância especial que para as culturas e valores espirituais dos povos interessados possui a sua relação com as terras ou territórios, ou com ambos, segundo os casos, que eles ocupam ou utilizam de alguma maneira e, particularmente, os aspectos coletivos dessa relação (OIT, 1989).

A CDB - Convenção sobre a Diversidade Biológica da Organização das Nações Unidas, de 1992, é o Tratado internacional que versa sobre os direitos bioculturais, conceituando no art. $2^{\circ}$, a diversidade biológica como:

[...] a variabilidade dos organismos vivos de qualquer fonte, incluindo, entre outras coisas, os ecossistemas terrestres e marinhos e outros ecossistemas aquáticos e os complexos ecológicos dos quais fazem parte; compreende a diversidade dentro de cada espécie, entre espécies e ecossistemas (ONU, 1992, tradução nossa). 
A CDB vincula os Estados-Parte ao dever de proteção, conservação, manutenção e restauração da natureza em si, conforme as alíneas "d", "f" e "j" do art. 8o, in verbis:

\begin{abstract}
Art. $8^{\circ}$ [...] d) Promoverá a proteção dos habitats e sistemas naturais e a manutenção de populações de espécies em ambientes naturais; [...] f) Reabilitará e restaurará ecossistemas degradados e promoverá a recuperação de espécies ameaçadas, através do desenvolvimento e implementação de planos ou outras estratégias de gestão; [... j) De acordo com sua legislação nacional, respeitará, preservará e manterá os conhecimentos, inovações e práticas das comunidades indígenas e locais que envolvem estilos de vida tradicionais relevantes para a conservação e uso sustentável da diversidade biológica e promoverá sua aplicação mais ampla [...] (ONU, 1992, tradução nossa).
\end{abstract}

Cabe ainda, citar a Convenção para a salvaguarda do patrimônio cultural imaterial da Organização das Nações Unidas para a Educação, a Ciência e a Cultura, de 2003, que destaca a interdependência que existe entre o patrimônio material cultural e natural com o patrimônio cultural imaterial da humanidade, conceituado no art. $1^{\circ}$ como:

[...] as práticas, representações, expressões, conhecimentos e técnicas junto com os instrumentos, objetos, artefatos e lugares culturais que lhes são associados - que as comunidades, os grupos e, em alguns casos, os indivíduos reconhecem como parte integrante de seu patrimônio cultural. Este patrimônio cultural imaterial, que se transmite de geração em geração, é constantemente recriado pelas comunidades e grupos em função de seu ambiente, de sua interação com a natureza e de sua história, gerando um sentimento de identidade e continuidade e contribuindo assim para promover o respeito à diversidade cultural e à criatividade humana. Para os fins da presente Convenção, será levado em conta apenas o patrimônio cultural imaterial que seja compatível com os instrumentos internacionais de direitos humanos existentes e com os imperativos de respeito mútuo entre comunidades, grupos e indivíduos, e do desenvolvimento sustentável (UNESCO, 2003).

No art. $2^{\circ}$, da referida Convenção se reconhece a manifestação do patrimônio cultural imaterial, entre outros campos, nas tradições, nas práticas sócias e rituais e nos conhecimentos e práticas relacionadas à natureza e ao universo (UNESCO, 2003). 
Assim, a relação homem-natureza, base do sistema jurídico biótico, é evidenciada nas manifestações sociais e espirituais que envolvem o meio ambiente, como o caso do rio Amazonas, que comanda a vida com suas águas transnacionais que fluem das nascentes a foz, cruzando fronteiras, sendo parte de estórias e culturas tradicionais e indígenas que vivem em suas margens. Tais populações devem, em prol de garantirem seus direitos à dignidade, a água e ao ambiente saudável, no âmbito do Direito Internacional, do Tratado de Cooperação Amazônica, não simplesmente nas jurisdições de cada Estado-Membro, postularem pelo reconhecimento da natureza como sujeito de direitos, do rio Amazonas, para que este possa continuar sendo vida das atuais e futuras gerações.

\section{CONCLUSÃO}

A problemática que estimulou essa pesquisa foi a de verificar de que forma seria possível assegurar à natureza o direito de serem "sujeitos de direito", evitando que o homem promovesse a sua extinção ou degradação.

Os objetivos da pesquisa foram cumpridos, uma vez que se analisou a legislação nacional e internacional, bem como a doutrina e jurisprudência a respeito, para se responder à problemática levantada.

Conclui-se que é fundamental o reconhecimento dos Direitos da Natureza, dos bens ambientais, como entidades dotadas de personalidade jurídica, em que pese os valores culturais e ancestrais dos povos tradicionais e das comunidades indígenas que vivem, harmonicamente, há anos nos respectivos territórios, com fundamento nos "direitos bioculturais".

No âmbito jurídico global, os casos do rio Atrato, na Colômbia, e do rio Whanganui, na Nova Zelândia, e a constitucionalização dos Direitos da Natureza no Equador, na Bolívia e no México evidenciam as atuais percepções ecológicas do novo constitucionalismo latino-americano, direcionadas ao enfrentamento do colapso climático global, com a quebra do paradigma de uso desarrazoado do meio ambiente, como mercadoria, pelo homem. 
A solução se mostra possível, se o firmado no texto normativo do Tratado de Cooperação Amazônica for interpretado de acordo com os princípios jurídicos bióticos da Convenção sobre Diversidade Biológica e o rio Amazonas, em face das tradições, das práticas sociais e rituais das comunidades que vivem em suas margens, for reconhecido como patrimônio cultural imaterial, por sua grandiosidade natural e pela diversidade cultural que nele existe e dele faz parte: o rio somos nós, nós somos o rio.

\section{REFERÊNCIAS}

ANA, Agência Nacional de Águas. GEO-BRASIL: Recursos Hídricos. Brasília, DF, 2017. $\quad$ p. $30 . \quad$ Disponível em: $<$ http://arquivos.ana.gov.br/wfa/sa/GEO\%20Brasil\%20Recursos\%20H\%C3\%ADdrico s\%20-\%20Resumo\%20Executivo.pdf>. Acesso em: 10 jun. 2019.

BOLÍVIA. Ley no 071, de 21 de diciembre de 2010. Ley de derechos de La Madre Tierra. Disponível em: <http://files.harmonywithnatureun.org/uploads/upload656.pdf>. Acesso em: 2 jun. 2019.

BOYD, David R.. The Rigths of Nature: A legal revolution that could save the World. ECW Press, 2017.

BRASIL. Decreto n. 85.050, de 18 de agosto de 1980. Promulga o Tratado de Cooperação Amazônica. Planalto, Brasília, DF, 1980.

BUENO, Eduardo. Náufragos, Traficantes e Degredados: As primeiras expedições ao Brasil. Rio de Janeiro: Sextante, 2016.

CCRC - Corte Constitucional de Republica de Colombia. T-622: Sentencia sobre El Río Atrato, 10 nov. 2016.2 Disponível em: $<$ http://cr00.epimg.net/descargables/2017/05/02/14037e7b5712106cd88b687525dfe b4b.pdf>. Acesso em: 10 jun. 2019.

DICIO. Dicionário Online de Português, 2019. Disponível em: <https://www.dicio.com.br/natureza/>. Acesso em: 6 jun. 2019.

DIEGUES, Antonio Carlos. Água e cultura nas populações tradicionais brasileiras. In: I Encontro Internacional sobre governança da água. São Paulo: USP, 2007.

EQUADOR. Constituicion de La Republica del Ecuador. 2008. Disponível em: $<$ http://files.harmonywithnatureun.org/uploads/upload657.pdf>. Acesso em: 2 jun. 2019. 
ILA - International Law Association. The Helsinki rules. Helsinque, 1966. Disponível em: <https://www.internationalwaterlaw.org/documents/intldocs/lLA/Helsinki Rulesoriginal with comments.pdf>. Acesso em: 10 jun. 2019.

MAZZUOLI, Valério de Oliveira. Soberania e proteção internacional dos direitos humanos. In: Soberania: antigos e novos paradigmas. Rio de Janeiro: Freitas Bastos, 2004.

MÉXICO. Constitución Política de La Ciudad de México, 2017. Disponível em: $<$ http://files.harmonywithnatureun.org/uploads/upload687.pdf>. Acesso em: 2 jun. 2019.

NADER, Paulo. Introdução Estudo do Direito. Rio de Janeiro: Forense, 2008.

NASCIMENTO, Fernanda Souza do. Relatório final: Poluição da água da Bacia Amazônica. In: Projeto GEF Amazonas. Brasília: OTCA/GEF/PNUMA, 2015. p. 3. Disponível em: <http://otca.info/gef/uploads/documento/5349dATIVID.III.3.2 FERNANDA.NASCIMENTO RELATORIO 5.pdf>. Acesso em: 10 jun. 2019.

NASCIMENTO, L. L.; POZZETTI, Valmir César. A necessidade do gerenciamento das águas doces compartilhadas na Pan-Amazônia. In: Conpedi Law Review, v. 3, n. 1, 2017.

Disponível

em: $<$ https://www.indexlaw.org/index.php/conpedireview/article/view/3689>. Acesso em: 2 jun. 2019.

$\mathrm{NASH}$, James A. The Case for Biotic Rights. In: Yale Journal of International Law, v. 18, 1993. Disponível em: <http://digitalcommons.law.yale.edu/yill/vol18/iss1/7>. Acesso em 2 jun. 2019.

NZL, New Zealand Legislation. Act 2017 № 7. Te Awa Tupua (Whanganui River Claims Settlement), $2017 . \quad$ Disponível em: $<$ http://www.legislation.govt.nz/act/public/2017/0007/latest/whole.htm|\#DLM6831460 >. Acesso em: 2 jun. 2019.

OIT, Organização Internacional do Trabalho. Convenção no 169 sobre Povos Indígenas e $\quad$ Tribais, $1989 . \quad$ Disponível em: $<$ http://www.ilo.org/brasilia/convencoes/WCMS 236247/lang--pt/index.htm>. Acesso em: 2 jun. 2019.

ONU, Organização das Nações Unidas. Convenção de Regulamentação dos Usos Não-navegáveis de cursos d'água Internacionais. Nova lorque, 1997. Disponível em: $\quad$ <https://treaties.un.org/doc/Treaties/1998/09/19980925\%200630\%20PM/Ch XXVII 12p.pdf>. Acesso em: 10 jun. 2019. 
ONU, Organização das Nações Unidas. Convenção sobre a Diversidade Biológica. Rio de Janeiro, 1992. Disponível em: <https://www.cbd.int/doc/legal/cbd-es.pdf>. Acesso em: 6 jun. 2019.

POZZETTI, Valmir César e NASCIMENTO, Leonardo Leite. A necessidade do gerenciamento das águas doces compartilhadas no pan amazônia. Revista Conpedi Law Review. V. 3 n.1, Costa Rica, 2017

REALE, Miguel. Lições Preliminares de Direito. São Paulo: Saraiva, 1976.

RIBEIRO, Nelson de Figueiredo. A questão Geopolítica da Amazônia: da soberania difusa a soberania restrita. Brasília: Senado Federal, 2005.

SHELTON, Dinah. Nature as a legal person. In: VertigO - la revue électronique em sciences de l'environnement [Online], 2015. Disponível em: <http://journals.openedition.org/vertigo/16188>. Acesso em: 2 jun. 2019.

SHIVA, Vandana. Guerras por água: privatização, poluição e lucro. São Paulo: Radical Livros, 2006.

SOUZA, Márcio. Breve história da Amazônia. São Paulo: Marco Zero, 1994.

STF, Supremo Tribunal Federal. RE 835558/SP. Rel. Min. Luiz Fux, Tribunal Pleno, julgado em 09 fev. $2017 . \quad$ Disponível em: $<$ http://www.stf.jus.br/portal/jurisprudencia/listarJurisprudencia.asp?s1=\%28NATURE ZA\%29\%28ambiental\%29\%2ETEMA\%2E\&base=baseAcordaos\&url=http://tinyurl.co m/y9zj2c3k>. Acesso em: 2 jun. 2019.

TOCANTINS, Leandro. O rio comanda a vida: uma interpretação da Amazônia. 9. Ed. Manaus: Editora Valer, 2000.

UNESCO, Organização das Nações Unidas para a Educação, a Ciência e a Cultura. Convenção para a salvaguarda do patrimônio cultural imaterial. Paris, 2003. Disponível em: <http://unesdoc.unesco.org/images/0013/001325/132540por.pdf >. Acesso em: 5 jun. 2019.

USSC, SUPREME COURT OF THE UNITED STATES. Sierra Club v. Norton (405 U.S. 727), $1972 . \quad$ Disponível em: $<$ http://files.harmonywithnatureun.org/uploads/upload684.pdf >. Acesso em: 2 jun. 2019. 